\title{
Arbor
}

\section{El hombre del cuadro (fabulación para escépticos)}

\section{Eduardo Roca Roca}

Arbor CLXXVIII, 703 (Julio 2004), 469-480 pp.

-Tengo que formular unas serias reivindicaciones, aclarando que no se trata de una reclamación sino una autentica reivindicación de los derechos que me corresponden y que históricamente han sido olvidados de una forma consciente y determinada, no sólo por los propios dioses sino también por mis contemporáneos, los artistas y aquellas personas que me han conocido.

Me sorprendió enormemente esta voz, porque era una tarde de agosto en la que me sentía un tanto somnoliento y pensaba que momentáneamente me había dormido aunque de forma muy superficial, pero me quedé mirando el cuadro que había enfrente de mi y me pareció que la voz reivindicatoria procedía de allí; me quedé mirándolo fijamente era un cuadro que se había ido trasmitiendo a través de diversas generaciones en mi familia y que había llegado a aquella habitación un tanto oscurecida por la caída de la tarde, y que siempre me había llamado la atención, tanto a mi como a otras personas que, en esta media luz, se sentían impresionados por aquel cuadro oscuro con una figura arropada, con mirada un tanto atravesada que quizá reflejaba unas ideas no muy amistosas; incluso a los pequeños aquel cuadro o aquel retrato de este hombre, que no era nada grato, siempre les había inspirado un cierto recelo, y si se quiere, hasta miedo, porque en esta luz un tanto apagada o semi apaga$\mathrm{da}$, en los momentos del atardecer tenia un cierto aire siniestro. $\mathrm{Me}$ quedé mirando al cuadro y me dió la impresión de que aquella barba entrecana se había movido y que los labios del personaje también se habían movido. Pero era imposible, porque los cuadros tienen dos características, primero no hablan, segundo los personajes que en ellos existen o fi- 
guran retratados no formulan reivindicaciones o reclamaciones que es lo que aquel señor me había parecido que decía.

En estas reflexiones volvió a oírse la voz. No era una voz siniestra ni que pudiera infundir miedo de ninguna naturaleza, pues tenía un sentido amistoso, era una voz varonil, sonora y no inspiraba desconfianza de ninguna clase, entonces volví a oírla cuando decía:

-He sido yo el que hablo, he sido yo, porque, repito, tengo que formular serias reivindicaciones históricas lo cual es algo que en los tiempos actuales se suelen formular por todos los ciudadanos y en todos lo países, por las razones más insospechadas y con las bases menos fundamentadas. Yo tengo una fundamentación y una tradición histórica de mis reivindicaciones. Que conste que no se trata de una reclamación porque no sé a quien podría dirigirse la misma, a estas alturas el tiempo ha pasado y fluye, mana, cuando esta reivindicación debió de formularse hace quizás siglos, a lo mejor hasta milenios, pues tendré que referirme a un tiempo que medido en la forma en que lo hacéis hoy día puede ser de mil quinientos años; no pongas esa cara de extrañeza porque me siento seriamente discriminado, olvidado y totalmente alejado de una serie de derechos que hoy podrían tener el carácter fundamental en cualquier país civilizado, o al menos así lo entiendo por mi parte, porque tengo que hacer, por lo menos, tres planteamientos: uno reivindicar mi derecho de propiedad intelectual; dos, en segundo lugar, reclamar también la autoría de algo que ha sido siempre mío, y por último, una reivindicación de protesta porque alguien, ya te diré quien, me encarceló en este cuadro casi mil años después de mi desaparición de esta tierra, y a la cual habré de hacer también alguna referencia un poquito más arriba o un poquito más abajo en mi fábula que titulé «La hormiga», me refiero a la situación de aquel hombre agricultor que no solo recogía lo suyo sino que también envidiaba a los ajenos y deseaba constantemente los frutos de sus vecinos por lo que Zeus se irritó y lo transformó en hormiga, pero aún bajo la forma de este pequeño animal no cambió su costumbre, pues iba de un lado para otro por los campos y la hormiga recogía el trigo y la cebada de los otros, y la recoge para si misma, y concluye Esopo diciendo lo siguiente «esta fábula muestra que los malvados por naturaleza aunque se les castigue sobremanera no cambian su forma de ser», y en mi fábula titulada «El ratón y la rana» se recoge aquella narración en la que un ratón se hizo amigo de una rana y al final ésta lo convenció para que se echara al agua con ella, ahogándose el ratón y lo vió un ave y lo cogió entre las garras y como la rana estaba atada al ratón también ella sirvió de 
comida al milano. La conclusión de esta fábula es la siguiente según Esopo: «aunque alguien esté muerto, tiene fuerza para la venganza, pues la justicia divina cuida todo y devuelve lo mismo en compensación».

-Con esto que te estoy contando no trato de vengarme de nadie sino contar una realidad que sucedió hace muchos años, comentarte algo sobre mi vida y mi obra, y sobre todo, como antes decía, dejar constancia de que han existido después de mi vida una gran cantidad de escritores que con carácter general se llaman a sí mismos «fabulistas» aunque no sean nada más que simples imitadores míos, a veces, incluso, plagiadores como antes decía. Pero me causa un gran disgusto el hecho de que bastante tiempo después de mi muerte terrenal, allá por el Siglo primero, que vosotros llamáis después de Cristo, hubo un libro, yo creo que es un libelo, que bajo el título de «Vida de Esopo» aparte de poner de relieve mi origen como esclavo, se me retrata tremendamente feo, barrigón, canijo, de gran cabeza, hasta incluso bizco y además para completar la descripción que hace este desgraciado autor insiste en que era desdentado y un poco tartamudo; no es cierto que yo fuera de esta manera y además nunca debió de conocerme el autor de tal panfleto ya que mis escritos superan en sabiduría y hacer bien las cosas, a cualquier pensamiento que pueda tenerse en contra de mi figura material o personal que se encuentra muy por debajo de la inteligencia que puse de manifiesto a lo largo de mi obra, pues no se debe de valorar a las personas por su cuerpo sino por el interior de su cabeza. De todas formas siempre la sabiduría fué la base de la solución de todos los conflictos que se presentaron a lo largo de mi existencia. Sí tengo que decirte que a mi me encantaban los viajes, incluso arriesgados, y no te voy a decir que ello sea fácil en un esclavo que es vendido y revendido y que recorre diversos países cercanos a Grecia hasta que lo venden a un filósofo llamado Janto y junto a él tuve una serie de problemas, tristezas y alegrías ya que a su lado conocí importantes filósofos, entre los que dejé constancia de mi existencia a través de mis fábulas y sucedidos, a los que siempre se les reconoció la importancia del saber. No se ha dicho quizás con bastante claridad que fuí liberado, es decir, soy un liberto que, incluso mantuve con mi amo magníficas relaciones y con él viajé a los distintos países a los que antes me refería llegando incluso a Babilonia y a Egipto, si bien el final de mi vida fué muy complicado ya que el conocido Creso me mandó a Lesbos para que viera la forma de vida de aquella población, que consideré disoluta y que fustigué, con mis escritos, por lo cual los habitantes de Lesbos me persiguieron y al final me condenaron a muerte arrojándome por un profundo precipicio bajo la inexacta e injusta acusación de que había robado una 
copa que era del templo, pienso que los habitantes de Lesbos fueron castigados como consecuencia de esta mala acción con una importante epidemia de peste. Es posible que yo no fuese muy agraciado, sin embargo tuve un gran atractivo con las mujeres desde la propia esposa de mi amo, al que antes me he referido como mi liberador, Janto, y con su mujer y las esclavas de Janto pasé unas jornadas plenas de amor, de felicidad y de auténtico encanto en las que me trasmitieron amor y siempre, además conocimiento tanto ellas como nuestro común dueño.

«No es muy conocido mi viaje a Lesbos donde tuve la ocasión de conocer a la poetisa más grande que he tenido ocasión de tratar en mi vida y que se llamaba Safo, y también a su familia y en especial a su hermano y a sus sirvientas; con todos ellos tuve una profunda amistad, si bien Safo pensó que debía conquistarme ella, en vez de que lo hicieran sus esclavas o mantuviera una estrecha amistad con su hermano por lo cual fui expulsado de una forma quizás no muy digna de aquella hermosa isla de la que sigo conservando un magnífico recuerdo aunque sé que nunca más podré volver a ella.

«Pero no he hablado de mi obra que fué extensa, mucho más extensa de lo que se comenta por la crítica y los conocedores de la literatura griega, en estos días además se me atribuye el hecho de que lo único que hice fue recoger una serie de tradiciones y escribirlas, en parte tienen razón en cuanto el conocimiento y la realidad de alguna manera son limitados dentro de la actividad de los escritores, pero los temas eternos de la humanidad, el amor, la muerte, el bien hacer, el robo, etc., son ideas que siguen latiendo desde el principio del ser humano y se puede comprobar en estos antecedentes a los que me he referido. Siempre utilicé en mis obras, en vez de personas auténticas, a un conjunto de animales que adoptaban una actitud humana en cuanto a manifestar sus sentimientos para aportar unas conclusiones que en algún momento pudieran considerarse ácidas pero que siempre tuvieron absoluto deseo de instruir, hacer reflexionar a mis conciudadanos y en toda ocasión instruirles en el bien, en la bondad, en los valores humanos, etc.

«Es importante recordar en este momento que mi espíritu fue recogido por un dios menor al pie de aquel enorme desfiladero en que me arrojaron en Lesbos y, desde entonces, he vivido errabundo sin conseguir un descanso como el resto de los espíritus, ya que tenía que formular estas reivindicaciones a las que antes me he referido, en primer lugar en cuanto a los escritores de fábulas y en segundo lugar a la forma en que se ha tratado mi cuerpo, mejor dicho la imagen a que antes me he referido y que ha sido transmitida falseada e incierta hasta estos momentos. 
«Mi obra, y en especial mis fábulas, han sido conocidas a lo largo de casi un milenio y medio porque, valga un poco la digresión, creo que son expresivas y contienen siempre una enseñanza. Pero el problema mío consiste en que estos escritos incluso durante mi vida, fueron copiados, o aún mejor, plagiados por una serie de escritores griegos y después latinos. Tengo que decir que hubiera sido conveniente que tu hubieras leído mi obra en griego, en la que puedes apreciar la profundidad y expresividad de este maravilloso idioma hoy prácticamente desconocido, y que es utilizado como materia de enseñanza muy restringida, en muy escasas ocasiones y a escasas personas. La realidad es que el desconocimiento del griego y, luego, más tarde del idioma latino, genera una forma de analfabetismo histórico que hoy se muestra de una manera especial en cuanto los jóvenes, y los menos jóvenes, apenas si saben o conocen unas cuantas palabras latinas y no sólo no conocen ninguna palabra griega sino que más bien lo que hacen es maltratar mi idioma materno tratando de encontrar el origen de determinadas palabras. Pero no es ocasión de realizar un estudio crítico de esta situación ahora sino decir que mi obra repito fué estudiada y plagiada a lo largo de la historia.

-Pero yo le pregunté a Esopo lo siguiente: ¿Por qué te mantienes en este planteamiento reivindicativo tanto tiempo después de haber desaparecido o al menos de haber desaparecido de una forma física, e incluso simbólica, como me estás demostrando en este momento?

-No es cierto lo que dices, no es verdad lo que tratas de atribuirme, quiero hacer estas reclamaciones y dejar constancia de lo que he dicho con anterioridad, pues el propio Zeus me prometió llevarme al Olimpo e incluso como premio a mi trabajo, convertirme en el dios de la fábula, y así se lo hice recordar y se lo pedí de forma incisiva en uno de mis viajes que hice a la Sicilia griega donde existían los más exquisitos templos entre Catania y Agrigento, siendo quizás el mas importante de todos el dedicado al dios Zeus, que más tarde llamarían los romanos Júpiter. Pues bien Zeus no se dignó en atender mi propuesta a pesar de haber sido él quien me salvó de la muerte espiritual, pero en aquel momento me dijo que era imposible que me elevara a la categoría de dios del Olimpo por una razón muy sencilla y es que los dioses aunque llevaran una túnica blanca tan hermosa como la mía, no eran tan feos como yo, y cuya explicación me dejó perplejo porque, seguidamente, me dijo que si yo lo deseaba podría mantener mi alma, mi espíritu, en un estado de vida latente a lo largo del tiempo futuro en el que podría conocer aventuras y acontecimientos en los que no podría participar, ya que yo no existía, ni podía manifestarme de ninguna manera de forma corporal. Fué un premio, 
pero a la vez fué un castigo. Yo hoy tengo que confesar que he padecido mucho y que aún no he llegado a la paz definitiva.

-¿Y por qué no has conseguido la paz definitiva?, te pregunto Esopo, porque tu situación es ideal, no tienes problemas, no tienes preocupaciones, un espíritu no necesita ni habitación, ni vestido, ni comida, de forma que tienes resueltas todas las necesidades básicas de un ser humano.

-Pero ten en cuenta que hay una cosa que sí he conservado, y es la forma en que fuí tratado por mis compañeros y los llamados amigos escritores que, como antes te decía, me copiaron, bien traduciéndome del griego al latín, o bien adoptando directamente las mismas ideas y las mismas palabras utilizadas por mí. No quiero que se tome esto en un sentido equívoco porque he de referirme a Fedro que tradujo mi obra del griego al latín y prácticamente se la apropió aunque en su primer libro, en el prólogo viene a reconocer que soy autor de importantes obras, pero este reconocimiento no es bastante. Si eres capaz de entender un poquito de latín lee el Prólogo que Fedro escribe a sus obras que es verdaderamente ilustrativo ya que en el mismo dice lo siguiente:

Aesopus auctor quam materiam repperit,

Hanc ego polivi versibus senariis

Duplex libelli dos est: quod risum movet,

Et quod prudenti vitan consilio monet.

Calumniari si quis autem voluerit,

Quod arbores loquantur, non tantum ferae,

Fictis iocari nos meminerit fabulis.

Y que se puede traducir de la siguiente forma:

«La materia que Esopo ideó como su creador, yo la he perfeccionado en versos senarios. El propósito del librito es doble: por una parte, mover a la risa y, por otra, guiar con su consejo la vida del prudente.

Pero si alguien quiere censurar el hecho de que hablen los árboles y no sólo las fieras, tenga presente que nosotros bromeamos con fábulas inventadas."

«Es decir Fedro casi cuatrocientos años después de mi muerte reconoce que yo fui el creador de la fábula pero que él la ha perfeccionado y da a entender que él es el creador de todo lo que viene a continuación. Son muchas las fábulas que Fedro se apropia quizás pensando que el es un poco el continuador mío y, de otra parte, que él también fue un esclavo liberto de Augusto, y que esto le daba libertad para machacar mi obra 


\section{El hombre del cuadro}

y apropiársela. Pienso que hay unas serie de fábulas que literalmente traduce como suyas Fedro, como "la zorra y la tortuga», «el lobo y el cordero», «el enfermo y el médico», «las ranas que pedían un rey», aquella otra de la rana que se ató al ratón a la que antes me he referido, etc., pero como no es este el momento de contar una por una todas las coincidencias sí quiero destacar que Fedro, en primer lugar, realizó una serie de alusiones a mi persona como se puede comprobar en distintas ocasiones por ejemplo la fábula tercera del libro segundo, o la fábula tercera del libro tercero, sobre Esopo y el campesino mientras que las referencias anteriormente citadas se titularon por Fedro « Esopo a un hombre acerca del éxito de los malvados» o la fábula quinta del libro tercero «Esopo y el indolente», él mismo cuando se autocita en la fábula veintidos, del libro cuarto, y la fábula novena del apéndice, que luego se traduce como ejemplo de la literatura greco-italiana que lleva un título en el que de nuevo aparece mi nombre, como ocurre en otras muchas fábulas de Fedro como: «El padre de familia y Esopo» que es la fábula doce, o «Esopo y el vencedor de lucha», «Esopo y su dueña», «Esopo y el esclavo prófugo», o «La ramera y el joven».

«Como antes te dije, las generaciones actuales sois auténticos analfábetos del idioma griego por ello te hago la traducción de una de mis fábulas que se llama «El lobo y el cordero»:

«Un lobo que vió a un cordero beber en un río quiso devorarlo con un pretexto razonable. Por eso, aunque el lobo estaba situado río arriba, le acusó de haber removido el agua y no dejarle beber. El cordero le dijo que bebía con la punta del hocico y que además no era posible, estando él río abajo, remover el agua de arriba; mas el lobo, al fracasar en ese pretexto, dijo: «El año pasado injuriaste a mi padre». Sin embargo, el cordero dijo que ni siquiera tenia un año de vida, a lo que el lobo replicó: «Aunque tengas abundantes justificaciones, no voy a dejar de devorarte, porque tu padre habló mal de mí».

La fábula muestra que no tiene fuerza una defensa justa con quienes tienen la voluntad de hacer daño.

Fedro traduce al latín esta fábula en la siguiente forma:

Ad rivum eumdem Lupus et Agnus venerant,

Siti compulsi superior instabat Lupus,

Longeque inferior Agnus. Tunc fauce improba

Latro incitatus iurgii causam intulit.

«Cur, inquit, turbulentam fecisti mihi

Aquam bibenti?» Laniger contra timens: 
«Qui possum, quaeso, facere quod quereris, Lupe?

A te decurrit ad meos haustus liquor».

Repulsus ille veritatis viribus:

«Ante hos sex menses male, ait, dixisti mihi».

Respondit Agnus : Equidem natus non eram».

Pater, hercule, tuus, inquit, maledixit mihi».

Atque ita correptum lacerat iniusta nece.

Haec propter illos scripta est homines fabula,

Qui fictis causis innocentes opprimunt.

Y como puedes tener alguna dificultad para traducir te diré que la traducción que hago al español es la siguiente:

«Al mismo arroyo habían llegado un lobo y un cordero impulsados por la sed; el lobo estaba más arriba y, mucho más abajo, el cordero. Entonces, movido por su insaciable voracidad, el ladrón sacó a relucir un motivo de diputa.

-¿Por qué -dijo- me has enturbiado el agua mientras estoy bebiendo?

El lanudo, amedrentado, replicó:

-¿Cómo puedo, por favor, hacer eso de lo que te quejas, lobo? La corriente fluye desde donde tú estás hasta donde yo bebo.

Aquél, contrariado por la fuerza de la verdad, dice:

-Hace seis meses hablaste mal de mí.

El cordero responde:

-¡Pero si no había nacido!

-Tu padre, por Hércules -dijo aquél-, habló mal de mí.

Y así, capturado, lo destroza con injusta muerte.

Esta fábula ha sido escrita a causa de esos hombres que avasallan a los inocentes por motivos inventados».

«Creo que ante la evidencia no hace falta ninguna otra cita sino remitirte a ti, y a quien pueda resultar interesado, a la comparación de otras muchas como las que anteriormente he citado. Pero no fué solamente Fedro liberto de Augusto, es decir, esclavo como yo liberado, el único que se inspiró en mi obra pues hubo otra serie de escritores latinos que también se inspiraron y pasó esta técnica al mundo occidental, de origen latino donde se han reproducido de forma directa o indirecta, o que han inspirado, por ejemplo en español a satíricos o fabulistas como Iriarte o Samaniego.

«Esta es, pues, la primera de mis reivindicaciones. La segunda se refiere a la necesidad de reivindicar mi propia imagen porque me estás 


\section{El hombre del cuadro}

viendo en este cuadro que hay enfrente de ti en el cual me encuentro prisionero, porque allá por el año 1640 lo pintó tu paisano, paisano como español, un pintor que fue célebre y llamado Don Diego de Velázquez que, además, me pintó de una manera crítica y satírica, mírame el escorzo del rostro poblado de una enorme barba, cubierto con este sombrero destartalado y semiembozado en una capa, que apenas si deja ver algo de mi rostro, y de mi mirada que el artista pinta con gesto torvo, acre y un tanto malvado que puede asustar a quien me contemple en la oscuridad.

-Tienes razón, Esopo porque en el lugar que te encuentras siempre que pasa alguien a tu lado, a una hora vespertina, con escasa luz, siempre causas una impresión negativa, y hasta los niños sienten esta impresión, no ya meramente contemplativa, sino de auténtico pánico pues esta pintura tuya produce miedo tanto aquí como en el museo.

-Tienes razón porque Velázquez me pintó de una manera un tanto satírica y agria como antes te he comentado, pero esto no es lo mas importante sino que además con este sentido critico Velázquez me ha hecho una faena tremenda, que consiste en haber capturado mi espíritu, que se encontraba en los ámbitos celestiales, flotando de una manera libre y me ha fijado, me ha introducido en el lienzo, y aquí llevo parado sin poder hacer nada desde 1640 como antes te decía. Claro es que al haberme «congelado» en este cuadro no puedo hacer nada, tengo que limitarme, desde hace cerca de cuatrocientos años y pico, a simplemente mirar y oír, no puedo decir nada, no puedo hablar nada, no puedo opinar, me encuentro aislado, atrapado y encarcelado. Por estas razones, hoy como he visto que tu atención se viene fijando en mi hace años cada vez que entras y sales de esta habitación, pensé que tenía que hacerte partícipe de alguna manera de mis problemas respecto de aquellos que me copiaron y de éste que me atrapó en un lienzo, y en él me encuentro sin poder opinar ni decir nada en absoluto. Quiero reivindicar mi figura, he sido maltratado a lo largo de la historia y desde aquel anónimo y desaparecido escritor que me describió en una presunta historia de mi vida, hace mil ochocientos o mil novecientos años, y por esta razón quiero liberarme de alguna manera de esta prisión que vengo sufriendo desde que fuí despeñado por los cretenses y los que les han sucedido, considerándome para siempre sin poder hablar ni decir nada. Pero antes hablaba que aún después de fallecer se puede tomar una venganza. La mía es quizás una venganza inocente pero tiene quizás su trascendencia como te voy a relatar a continuación. Velázquez debió de hacer la pintura de diversas imágenes o retratos, o presuntos retratos, por encargo de la corona y entre otros autores clásicos nos pintó a Menipo y a mí. El cuadro que aparece 
pintado como Menipo, en un principio, estaba destinado a reproducir mi imagen, esta imagen desgraciada, deshecha, estropeada, tartajeante, jorobada, sin dientes, etc., con su túnica blanca y de alguna manera atribuyó este retrato a mi persona, mientras que Menipo fue retratado en la forma en que me ves ahora con este sombrero, barba, y mirada torva, envuelto en esta capa que me proporciona un calor indecible durante los estíos calurosos de esta ciudad y que no me quita el frío durante los inviernos también crueles de la misma, y esto ya me sucedió en el propio taller de Velázquez, y se me sigue produciendo en la actualidad. Como ya he dicho me molestó que en el taller del pintor se me pintara en la forma en que se había hecho y, además, de forma equívoca confundiéndome con Menipo y atribuyéndome de alguna manera una figura inexacta, porque de verdad, repito, es insoportable este sombrero, esta barba, esta vestimenta. Pues bien cuando el pintor terminó de hacer los retratos, me miré y me vi verdaderamente desfigurado gracias a un espejo que existía al fondo del estudio, y que aparece en otras pinturas del señor Velázquez, y decidí entonces hacer un primer cambio y fué el de figurar a Menipo con la túnica y las exageraciones deformantes con que había pretendido pintarme a mí y, como mal menor, introducirme en el cuadro de Menipo en el que desde aquel momento apareció, o preferí que figurara mi retrato.

«Pero aquí no acaba la historia porque, mi venganza ha ido más lejos.

-Pero Esopo tú que siempre has combatido las malas costumbres de los hombres a través de su representación en la especie animal, en tus fábulas, no tiene sentido el que hables ahora de venganza y además respecto de un pintor que ni siquiera llego a conocerte, porque no existía ninguna constancia gráfica ni tuya ni de Menipo.

-Cierto es, me contestó Esopo, pero hay un error histórico, y el pintor debió de informarse al menos, pues creo que solo leyó o le dijeron que existía y que mi figura podía ser de una manera determinada, por parte de algún malintencionado que hubiese leído aquella relación, o biografía, de mi vida anónima de la que antes he hecho mención. Yo no pienso vengarme propiamente sino simplemente reivindicar, vuelvo a repetir, mi figura y mi forma de ser, porque no solo he perdido la posibilidad de ir al Olimpo sino que mi espíritu flotante, vuelvo a insistir, ha sido encarcelado en este cuadro. Yo, propiamente no me he vengando, si se quiere he hecho una broma pequeña, o modesta venganza, que ha consistido en lo siguiente: cuando vi los dos retratos juntos y el Maestro en el ángulo inferior derecho firmó con letra roja «Velázquez», pensé que había una forma de crear una situación que me liberara de las cárceles museísticas, del tropel de gente que me miraría mordaz y sonriente y para resolver el 


\section{El hombre del cuadro}

problema hice lo siguiente: pinté, porque tengo que afirmar, y que se sepa, que no solo tuve aficiones literarias sino también pictóricas porque fui amigo de algunos grandes escultores y pintores de la Grecia que me tocó vivir, y por lo tanto, podía intentar la realización de una broma, que consistió en lo siguiente: hice una reproducción exacta del cuadro pintado y lo sustituí por el original, y en el taller del maestro dejé la copia con una nota de un discípulo suyo que había marchado a Italia, y para la identificación del presunto original, hice lo siguiente: donde había puesto la firma Velázquez (en la parte inferior derecha del cuadro) puse la indicación siguiente: «Copia de Velásquez». Así pues el Museo en que está «colgado» es esta copia, que pinté como broma, más que venganza y reivindicación de mi forma de ser, y el original tuvo una serie de «aventuras» pasó por distintas manos y ahora esta aquí, con esta indicación que dice «copia de Velázquez» pero que es el original. Solamente quiero pedirte un pequeño favor: estoy molesto porque el tiempo ha oscurecido la imagen que se recoge de mi persona y de lo poco y mal que se ve de mi cuerpo físico, y el favor que te pido consiste en que una mano amiga me limpie, $o$, si lo prefieres, que me lave la cara y la vestimenta para que se pierda este color tremendamente oscuro que lo único que produce es este temor y miedo entre los pequeños, y de recelo para las personas mayores. Sé que conoces personas perfectamente capacitadas para hacerme este pequeño favor, a la vez que a ti te hago otro y es el que conozcas que tienes en tu casa un auténtico «Velázquez».

«Nunca he sido amigo de recomendaciones pero, en este momento, si debo hacerte una y es que la persona que puede hacer esta limpieza de cara y de cuerpo tengo entendido que se llama Amelia y su nombre tiene un significado especial porque sabrá mantenerme limpio sin que sea necesario que me recorte las barbas o que me quite el sombrero, que estoy dispuesto a seguir conservando, teniendo en cuenta que procede de una buena mano y que seré también limpiado por otra también buena, que sabrá guardar con discreción los secretos que te he confiado en este atardecer veraniego.

«Para terminar definitivamente, debo recordar que estoy dolido también con Platón ya que en alguno de sus diálogos, me estoy refiriendo a «Fedro», le dedica una elogiosa actitud personal e intelectual al mismo, al que incluso en algún momento le atribuye una serie de caracteres contrarios a la realidad, llegando a afirmar que es un ser divino por sus discursos, a la vez que «sencillamente admirable». No me parece mal esta afirmación que hace Platón, que pone en boca de Sócrates, pero no puedo olvidar, y me duele esta mención, pues Platón se olvida completa- 
mente de mí y que fuí el inspirador, o aún más, el padre literario del fabulista Fedro, y que si no fué, como antes he dicho, un plagiario total, por lo menos debió de citar mis fábulas en algún lugar del diálogo que Platón recoge entre Sócrates y Fedro, y haberme dedicado, quizá dentro de lo que fué la consideración del amor en esta obra, una pequeña esquina, un pequeño rincón, a mi y a mi obra, porque creo que si no lo hice mejor que Fedro, tampoco lo hizo éste mejor que yo, pues escribí mis fábulas varios cientos de años antes, por que, en todo caso soy mas antiguo que Fedro, es decir, soy como cuatrocientos años más viejo que Fedro y la vejez debe de ser respetada y tenida en cuenta incluso por los más eximios escritores y filósofos.

«Toda fábula tiene su moraleja que, en este caso, es doble:

-el plagiario difícilmente supera al autor copiado,

-no es oro todo lo que reluce; es buena la copia que se conserva de mi retrato en el museo, pero el original lo estás contemplando tú en estos momentos. Consérvalo y cuídalo. Recuerda siempre nuestra conversación porque creo que mis reivindicaciones han sido atendidas, y ya vivo en el Olimpo la mejor de mis Fábulas.

-Gracias, Esopo, le contesté pero el «hombre del cuadro», permaneció inmóvil, en un silencio de siglos. 